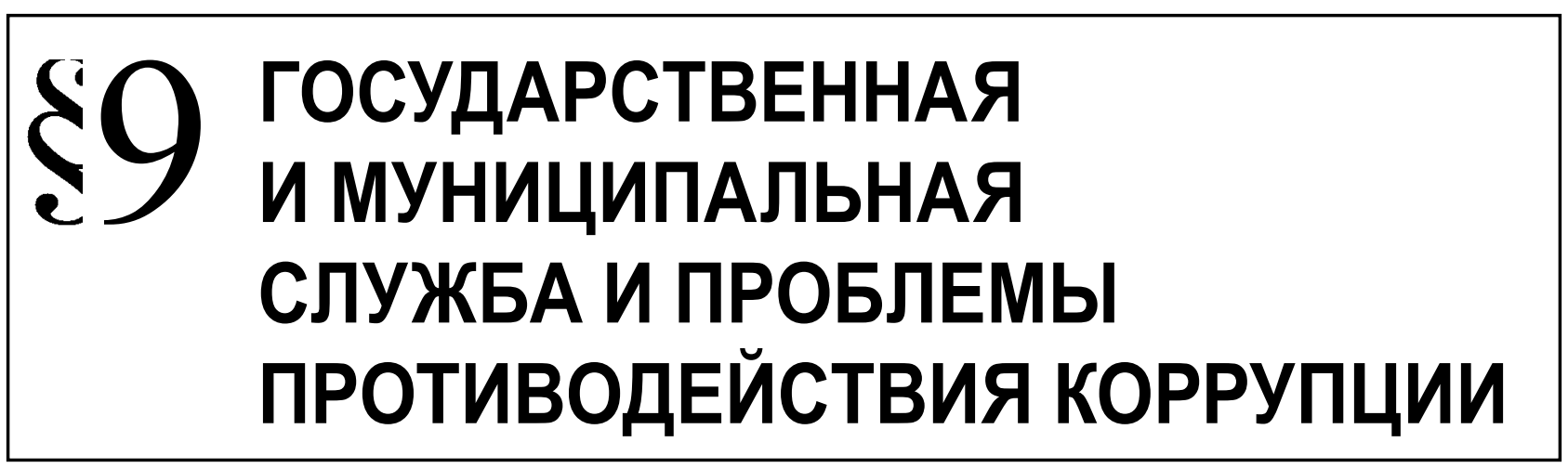

Белова М.А., Сорочкин Р.А.

\title{
СУБЪЕКТЫ КОРРУПЦИОННЫХ ПРЕСТУПЛЕНИЙ В ГОСУДАРСТВАХ АНГЛО-САКСОНСКОЙ ПРАВОВОЙ СИСТЕМЫ: ОСНОВНЫЕ МЕТОДОЛОГИЧЕСКИЕ «ИНСТРУМЕНТЫ»
}

\begin{abstract}
Аннотация: Предметом настоящего исследования стала англо-саксонская правовая система, как одна из наиболее распространенных в мировой юридической практике. Кроме того, следует отметить, что многие государства данной правовой системы добились больших, чем Российская Федерация, успехов в противодействии коррупции, и, возможно, заимствование их опыта могло бы дать положительные результаты в отечественной практике.Возможно, результаты анализа различных методологических подходов, применяемых при построении норм о субъекте коррупционного преступления, основанные на международном и зарубежном опыте, помогут ученым сформулировать универсальную систему критериев эффрективности национального уголовного законодательства в зависимости от того, насколько полно им предусмотрены те категории субъектов коррупционных преступлений, чьи общественно опасные деяния в мировой практике и составляют уголовно наказуемую коррупцию. Авторами на основе использования сравнительно-правового метода проанализирован широкий спектр архивных материалов, научная литература, материалы периодической печати. Применение формально-юридического метода позволило сформулировать авторские определения. Отечественное уголовное законодательство должно, по нашему мнению, органично сочетаться с уголовным законодательством зарубежных государств в целях обеспечения функционирования единой межгосударственной правовой системы противодействия коррупции как виду преступности. Оно должно отвечать современным коррупционным вызовам и своевременно криминализировать самые опасные для общества формы коррупции. Также оно должно содержать в себе определенные принципы, позволяющие (разумеется, при соблюдении принципов законности и вины) незамедлительно реагировать в рамках уже предусмотренных уголовным законом (Особенной частью Уголовного кодекса Российской Федерации (далее -УК РФ)) составов преступлений на появляющиеся новые способы, методы и формы коррупционных преступлений.

Ключевые слова: коррупция, зарубежное право, субъект коррупционного преступления, противодействие коррупции, юридическая техника, англо-саксонское право, организованная преступность, бланкетные правовые нормы, ответственность корпорации, профилактика коррупции.
\end{abstract}

$\mathrm{T}$ Тенденция глобализации мировой экономики, усилившаяся в последние десятилетия, оказывает значительное влияние и на отечественное уголовное законодательство. ${ }^{1}$ Российская

\footnotetext{
Примером такого влияния является появление норм об ответственности иностранных должностных лиц, об ответственности за торговлю людьми и ряда других.
}

Федерация, находясь между Востоком и Западом, объективно вынуждена взаимодействовать с различными правовыми системами иностранных государств. Подобное взаимодействие должно быть успешным для защиты прав и законных интересов граждан и субъектов предпринимательской деятельности, в том числе для защиты от коррупционных преступлений. 
Отечественное уголовное законодательство должно, по нашему мнению, органично сочетаться с уголовным законодательством зарубежных государств в целях обеспечения функционирования единой межгосударственной правовой системы противодействия коррупции как виду преступности. Оно должно отвечать современным коррупционным вызовам и своевременно криминализировать самые опасные для общества формы коррупции. Также оно должно содержать в себе определенные принципы, позволяющие (разумеется, при соблюдении принципов законности и вины) незамедлительно реагировать в рамках уже предусмотренных уголовным законом (Особенной частью Уголовного кодекса Российской Федерации (далее - УК РФ)) составов преступлений на появляющиеся новые способы, методы и формы коррупционных преступлений. Правоприменительной проблемой следует признать тот факт, что законодатель не дал ни перечня, ни определения «коррупционных преступлений»².

В связи с этим мы посчитали необходимым исследовать методологические аспекты юридической техники, наблюдающиеся при формулировании в зарубежном уголовном законодательстве положений о различных видах субъектов коррупционных преступлений. При этом ставились задачи:

- выявить факторы, в силу действия которых применена именно данная методология построения уголовно-правовых норм;

- выявить существенные признаки конкретной методологии.

Возможно, результаты анализа различных методологических подходов, применяемых при построении уголовно-правовых норм о субъекте коррупционного преступления, основанные на международном и зарубежном опыте, помогут ученым сформулировать универсальную систему критериев эффективности национального уголовного законодательства в зависимости от того, насколько полно им предусмотрены те категории субъектов коррупционных преступлений, чьи общественно опасные деяния в мировой практике и составляют уголовно наказуемую коррупцию.

Сегодня на планете широко распространены 3 правовые системы: англо-саксонская, романо-германская и мусульманская. Российская Федерация ведет постоянную совместную работу с государ-

2 Букалерова Л.А., Копылов М.Н. К вопросу о понятии «коррупционные преступления» Общество и право. 2012. № 1. C. 105-109. ствами, чье уголовное законодательство «исповедует» принципы какой-либо из этих правовых систем.

Предметом настоящего исследования стала англо-саксонская правовая система, как одна из наиболее распространенных в мировой юридической практике. Кроме того, следует отметить, что многие государства данной правовой системы добились больших, чем Российская Федерация, успехов в противодействии коррупции, и, возможно, заимствование их опыта могло бы дать положительные результаты в отечественной практике. ${ }^{3}$

В качестве объектов анализа в данном случаев использовано уголовное законодательство и значимые для его толкования бланкетные нормы Великобритании, ${ }^{4}$ Канады ${ }^{5}$ и Соединенных Штатов Америки. ${ }^{6}$ Данные государства являются родоначальниками и наиболее типичными представителями англо-саксонской правовой системы.

Изучение методологических подходов, применяемых в уголовном законодательстве вышеуказанных государств в отношении субъектов коррупционных преступлений, позволило, как нам кажется, выявить следующие общие методологические принципы англосаксонской правовой системы, действующие при формулировании положений о различных видах субъектов коррупционных преступлений.

1. Во-первых, национальное уголовное законодательство не содержит формального определения должностного лица либо иного лица - носителя полномочий государственной власти или власти, данной органам местного самоуправления, как субъекта коррупционного (или, к примеру,

\footnotetext{
3 При этом предметом нашего изучения являлись источники зарубежного уголовного законодательства конкретных государств, местная судебная практика и мнения зарубежных криминалистов.

4 См. напр.: Закон о коррупции в государственных органах 1889 г.; Закон о предотвращении коррупции 1906 г.; Закон об антитерроризме, преступлениях и безопасности 2001 г. и др.

5 См. напр.: Уголовный кодекс Канады; Закон о национальной обороне и др.

6 См., напр.: глава 11 раздела 18 Свода законов США «Взяточничество, подкуп, злоупотребление служебными полномочиями»; глава 93 Свода законов США «Государственные чиновники и служащие»; Федеральный закон «О борьбе с коррумпированными и находящимися под рэкетирским влиянием организациями» (Racketeer Influenced and Corrupt Organizations Act, или Rico Act) 1970 г.; Закон «О регистрации иностранных агентов» (закон FARA) 1938 г.; Закон «О подкупе иностранных должностных лиц» (FCPA) 1977 г.; Закон «О патриотизме» и др.
} 
должностного) преступления, выражающегося в совокупности определенных качественных признаков данного субъекта (как это делается в соответствующем отечественном законодательстве).

Так, в статье 118 Уголовного кодекса Канады есть упоминание о должностном лице, при этом в законе нет его качественных признаков. Лишь указывается, какой пост лицо занимает, а полномочия его (организационно-распорядительные, административно-хозяйственные) не приводятся: должностное лицо - лицо, занимающее государственный пост, либо назначенное или избранное лицо, выполняющее какие-либо государственные обязанности.

На наш взгляд, наличие подобного принципа нельзя расценивать как пробел в уголовно-правовом регулировании или иной недостаток работы местных законодателей, по следующим основаниям. Такая ситуация является частным отражением общего методологического подхода к уголовноправовой борьбе с коррупцией, традиционного для англо-саксонской правовой системы.

В соответствии с данным подходом законодатель не делает акцента на коррупции как самостоятельном родовом или видовом объекте состава преступления, а рассматривает ее как одну из разновидностей организованной преступности. Учитывая данную криминологическую позицию, а также фактически тесную взаимосвязь организованной преступности как с коррупцией, так и с иными наиболее опасными видами преступности, местные законодатели исходят из того, что подобный подход является наиболее практически оправданным и выступает в качестве комплексного средства борьбы с преступностью.

В качестве наглядной демонстрации реализации подобного подхода можно сослаться на уголовное законодательство США. Там, например, подлежит уголовной ответственности «за коррупцию» лицо, которое прямо или косвенно дает или обещает передать какие-либо ценности должностному лицу или частному лицу с намерением совершить на территории США террористические действия.

Полагаем, выражаясь терминами марксизма, что подобная «надстройка» имеет под собой некий объективный экономический «базис». Как указывалось выше в настоящем исследовании, экономический фактор является одним из самых значимых в том числе для построения системы антикоррупционных норм уголовного права. Великобритания, Соединенные Штаты Америки и Канада - государства с развитой рыночной экономикой, при этом основу ВВП исторически составляют результаты деятельности частных предприятий. Данные предприятия функционируют в том числе в наиболее социально значимых областях, таких как энергетика, медицина, оборонная промышленность и других. В этой связи подобные предприятия обладают и частью той компетенции, которая в государствах с иной, более непосредственно «огосударствленной» экономикой, с иными правовыми системами принадлежит органам государственной власти (в частности, органам государственного контроля (надзора)). Соответственно, определение каких-либо организационно-распорядительных и административно-хозяйственных полномочий, а также круга лиц, которым эти полномочия («государственные обязанности» по смыслу ст.118 УК Канады) принадлежат, делегировано руководству подобных предприятий и, полагаем, с трудом поддается унификации, поскольку организационные структуры бизнеса находятся в постоянном реформировании, обусловленном процессом конкурентной борьбы за рынок.

В силу этих причин, по нашему мнению, местный законодатель пошел по пути криминализации коррупции как разновидности организованной преступности. Подобный методологический подход имеет как свои положительные результаты, так и негативные стороны.

Как правило, в совершении коррупционных преступлений участвуют несколько лиц (например, группа - «взяткодатель - взяткополучатель»). Бизнес-структуры, развиваясь, постоянно реорганизуются. Такая реорганизация влечет и реорганизацию государственного аппарата. При этом социально-экономическое значение таких бизнес-структур для реализации государственных задач огромно, и государство должно обеспечить существование антикоррупционного уголовного законодательства, которое сможет эффективно профилактировать преступность, быть достаточно стабильным (не подвергаться ежегодному изменению), чтобы обеспечить информированность населения о соответствующих запретах, а также позволять реагировать на новые формы, методы, способы совершения коррупционных преступлений, с учетом появления новых сфер общественной жизни, в которые проникает коррупция.

Закономерно, на наш взгляд, что для соответствия таким приоритетам, продиктованным социально-экономической необходимостью, метод борьбы с коррупцией путем закрепления ограниченного перечня государственных или 
муниципальных служащих, становящихся субъектами коррупционных преступлений, вряд ли будет результативен. Применение такого подхода в условиях развитой рыночной экономики и делегирования негосударственным структурам функций государственного контроля не позволит правоохранительным органам достаточно эффективно пресекать коррупционные преступления, связанные с злоупотреблениями подобными контрольными полномочиями служащими частных корпораций. Кроме того, не будут реализованы в должной мере задачи по уголовно-правовой профилактике коррупции в собственно частном секторе, поскольку коррупционные по содержанию преступления будут квалифицироваться как экономические, и закономерно, что санкции за экономические преступления будут назначаться за коррупционные деяния. Могут возникать проблемы в случаях противодействия такой форме коррупции, как «торговля влиянием». Произойдет смещение акцентов уголовно-правовой борьбы с коррупцией на должностные и экономические преступления, а это, в свою очередь приведет к формированию тенденций работы правоохранительных органов, согласно которым выявление исключительно конкретных фактов хищений или злоупотреблений, а не всего круга лиц, входящих в преступную группу, является конечной целью деятельности правоохранителей. Соответственно, подобная правоприменительная практика приведет к тому, что абсолютное большинство оперативных разработок будет считаться успешными и формально завершаться в случае задержания единственного взяткодателя (взяткополучателя).

Напротив, вышеописанный методологический подход, характерный для англо-саксонской правовой системы, требует от полиции и иных правоохранительных ведомств выявления, документирования и пресечения в ходе оперативно-розыскных мероприятий не единичного факта коррупции, а организованной коррупционной деятельности

\footnotetext{
Представляется, что наиболее содержательное определение торговли влиянием содержится в ст.ст.432-11, 433-11 УК Франции. Согласно нормам данной статьи торговля пассивным влиянием имеет место, когда его совершают представитель власти либо частное лицо, использующее реальное или мнимое влияние на государственные органы; торговлю активным влиянием совершает третье лицо, предлагающее какую-либо выгоду лицу, являющемуся представителем государственной власти, либо частному лицу под предлогом, что оно может оказать определенное влияние на государственные органы.
}

преступной группы нескольких лиц (даже в случае единичного факта коррупции).

Вместе с тем, по нашему мнению, подобный методологический принцип может иметь и негативные стороны, о которых мы скажем ниже.

Методологический подход, в силу которого в уголовном законодательстве государств англо-саксонской правовой системы усматривается описанный выше принцип, сформировал еще несколько взаимосвязанных принципов аналогичной направленности.

2. В частности, в качестве самостоятельного класса субъектов коррупционных преступлений, помимо государственных и муниципальных служащих, выделяются физические лица, реализующие правосубъектность тех юридических лиц, которые осуществляют хозяйственную деятельность в наиболее стратегически важных отраслях экономики (имеющих значение для обеспечения обороноспособности, безопасности государства, обеспечения деятельности систем социального обеспечения, здравоохранения и т.п.).

Важно отметить в связи с этим, что здесь основанием для классификации и выделения отдельного класса субъектов коррупционных преступлений является не факт наличия государственной или муниципальной имущественной доли в акционерном (уставном) капитале каких-либо конкретных компаний (например, хозяйственных обществ), а сам факт осуществления юридическим лицом, даже принадлежащим на $100 \%$ частному собственнику, хозяйственной деятельности в определенной общественно важной сфере экономики. В случаях, когда в процессе подобной деятельности сотрудником такой компании совершается коррупционное преступление (например, дача взятки за получение государственного контракта), данное лицо будет относиться к вышеуказанному самостоятельному классу субъектов коррупционных преступлений.

Следует согласиться с Букалеровой Л.А., Гаврюшкиным Ю.Б., что для имплементации института уголовной ответственности юридических лиц в российское законодательство, повышения эффективности введения этого института придется еще многое продумать ${ }^{8}$.

Так, согласно уголовному законодательству Великобритании, предусмотрена уголовная от-

\footnotetext{
Букалерова Л.А., Гаврюшкин Ю.Б. К вопросу о введении института уголовно-правового воздействия в отношении юридических лиц // Пробелы в российском законодательстве. 2012. № 4. С. 169.
} 
ветственность за коррупцию «членов, служащих и должностных лиц корпораций, комиссий и иных публичных органов, действующих в национализированных областях промышленности». ${ }^{9}$ Ссылка на действие корпорации «в национализированных отраслях промышленности» и является способом отнесения виновного лица к вышеуказанному классу субъектов коррупционных преступлений.

Применение подобного приема юридической техники позволяет оперативно реагировать на повышение уровня коррупции в той или иной отрасли экономики путем ужесточения уголовно-правовой репрессии применительно к лицам, виновным в коррупционных преступлениях, связанных с предприятиями такой отрасли. Например, отнесение к таким «антикоррупционно значимым» отраслям экономики, осуществляемое через принятие бланкетных правовых норм, сферы жилищно-коммунального хозяйства может привести к признанию большинства преступных посягательств на имущество в этой сфере коррупционными деяниями, влекущими более строгое уголовное наказание в сравнении с наказанием за преступления против собственности. Разумеется, факт такого отнесения влияет положительным образом на профилактику умышленных корыстных преступлений в сфере жилищно-коммунального хозяйства. Таким образом, с помощью подобного метода осуществляется актуальная в конкретный момент времени профилактика коррупции; при этом она может производиться с помощью подзаконных нормативноправовых актов, период принятия которых в разы меньше, чем период принятия новых законов в уголовно-правовой сфере.

3. Лицо, совершившее мошенничество путем злоупотребления доверием в сфере предпринимательской деятельности, является субъектом коррупционного преступления.

В уголовном законодательстве государств англо-саксонской правовой системы присутствует исключительно широкая трактовка коррупции в частном секторе, в силу которой любое мошенничество, совершенное лицом путем злоупотребления доверием, признается коррупционным преступлением, и виновное лицо соответственно - его субъектом.

Так, согласно Закону Великобритании о предотвращении коррупции 1906 г., «агент»- любое лицо, служащее по найму или действующее в инте-

\footnotetext{
9 См.: Закон Великобритании о коррупции в государствен-
} ных органах 1889 г. ресах другого лица и лицо, являющееся служащим Короны или любого местного или публичного органа власти». В соответствии с нормами ст.121 (1) УК Канады предусмотрено такое коррупционное преступление, как торговля влиянием, состоящая в передаче предмета взятки «покупателем влияния» в пользу другого лица («продавца влияния»), при этом «покупатель» убежден, что «продавец» сможет добиться какого-либо решения в его пользу. При этом оба лица являются субъектами преступления (в российской практике подобное деяние квалифицировалось бы как мошенничество - преступление против собственности).

Принятый в англо-саксонской правовой системе вышеописанный в общих чертах методологический подход имеет, как указывалось выше, и некоторые, по нашему мнению, отрицательные стороны.

Применение этого подхода ориентировано во многом на решение задачи по уголовно-правовой профилактике коррупции в собственно частном секторе, с учетом социально-экономического значения последнего в условиях развитой рыночной экономики. В силу этого обстоятельства присутствует риск смещения акцентов уголовно-правовой борьбы с коррупцией на борьбу с собственно экономическими преступлениями. В случае реализации этого риска может возникнуть следующий «тренд» работы правоохранительных органов. Государственный правоохранительный аппарат акцентирует усилия своих антикоррупционных подразделений на создании статистических показателей в сфере противодействия коррупции за счет активного привлечения к уголовной ответственности мошенников, но совершивших общественно опасные деяния в сфере обычной предпринимательской деятельности, не связанной прямо или косвенно с распределением государственных или муниципальных финансовых средств, либо осуществляемой за пределами сферы вышеуказанных «национализированных отраслей промышленности». При этом задачи уполномоченных ведомств формально выполнены, несмотря на дублирование ими функций подразделений по борьбе с экономическими преступлениями. Но собственно коррупционная преступность как объект деятельности правоохранителей остается без внимания.

4. Юридические лица являются самостоятельным видом субъектов коррупционных преступлений.

Здесь зарубежный законодатель категорически не согласен с подходом, доминирующим в 
отечественной науке уголовного права. ${ }^{10}$ Так, согласно уголовному законодательству Великобритании «любая корпорация несет ответственность за преступления и проступки своих служащих или представителей, совершенные ими в процессе деятельности от имени корпорации. При этом уголовная ответственность корпорации возникает в том случае, когда противоправное деяние совершается лицом, контролирующим деятельность корпорации в таком объеме полномочий и на таком уровне, что можно полагать, что действие этого лица выражает намерение корпорации (ее директором, управляющим, секретарем или иным служащим корпорации с аналогичными функциями)». ${ }^{11}$

Представляется, что отнесение юридических лиц в категорию субъектов преступления в англосаксонской правовой системе объясняется прежде всего их ролью и значимостью в той экономической структуре, о которой было сказано выше.

Подводя итоги краткого анализа англо-саксонской правовой системы применительно к теме исследования, заключим, что у законодателей государств всех правовых систем наблюдаются определенные проблемы в установлении исчерпывающего перечня субъектов коррупционных преступлений. С учетом политических, социальных, экономических, религиозных и иных особенностей различных географических регионов представляется крайне сложным разработать универсальную методологию критериев оценки эффективности конкретного национального уголовного законодательства в отношении всего круга субъектов коррупционных преступлений.

Представляется, что с развитием процессов интеграции отечественной экономики в мировую глобальную экономику и соответственно с ростом значимости частного капитала в нашем уголовном законодательстве также произойдут изменения, связанные в том числе с расширением перечня субъектов коррупционных преступлений, совершенных сотрудниками частных корпораций, в связи с чем заимствование вышеописанных методологических «инструментов» может стать одним из результативных решений проблемы повышения эффективности государственной политики по противодействию коррупции.

\section{Библиография:}

1. Букалерова Л.А., Копылов М.Н. К вопросу о понятии «коррупционные преступления» Общество и право. 2012. № 1. C. 105-109.

2. Букалерова Л.А., Гаврюшкин Ю.Б. К вопросу о введении института уголовно-правового воздействия в отношении юридических лиц // Пробелы в российском законодательстве. 2012. № 4. С. 169.

3. Закон Великобритании о коррупции в государственных органах 1889 г.

4. Рагулина А.В., Спасенников Б.А. Человек (физическое лицо) как субъект преступления.// Черные дыры в российском законодательстве. №2. 2003;

5. Уголовное законодательство зарубежных государств в борьбе с коррупцией / Институт законодательства и сравнительного правоведения при Правительстве Российской Федерации. Под ред. Власова И.С. М. 2009. С.31.

6. Актуальные проблемы обеспечения законности и противодействия коррупции в системе Министерства внутренних дел Российской Федерации. Т. 3 / Костенников М.В., Куракин А.В., Овчинников Н.А.-М.: Маросейка, 2012.

10 «...Ни при каких обстоятельствах не могут быть признаны субъектами преступления юридические лица. Иное бы противоречило принципам уголовного права. Юридические лица не могут действовать ни умышленно, ни по неосторожности».// Лазарев А.М. Субъект преступления. Учебное пособие для студентов. ВЮЗИ.М. 1981. С.3. Аналогичную позицию занимают и другие ученые. См., напр.: Рагулина А.В., Спасенников Б.А. Человек (физическое лицо) как субъект преступления.// Черные дыры в российском законодательстве. №2. 2003; Семенов С.А. Специальный субъект преступления: Генезис и история. Учебное пособие. 2-е издание. Владимир. 2001. С.25; Толстой Ю.К. К теории правоотношения. Л.1959. С.10; Веберс Я.Р. Правосубъектность граждан в советском гражданском праве. Рига. 1976. С.19; Мицкевич А.В. Субъекты советского права. М.1962. С.30.

11 Уголовное законодательство зарубежных государств в борьбе с коррупцией / Институт законодательства и сравнительного правоведения при Правительстве Российской Федерации. Под ред. Власова И.С. М. 2009. С.31. 
7. Актуальные проблемы борьбы с экстремизмом, терроризмом и коррупцией: материалы межвузовской научнопрактической конференции, 12 мая 2011 г., г. Астрахань / Отв. ред.: Бичехвост А.Ф., Петрашова О.И., Пушкин А.И.Астрахань: Сорокин Роман Васильевич, 2011.

8. Актуальные проблемы борьбы с коррупцией в странах СНГ / Карпович О.Г., Николаев А.Т., Спирин М.С.-М., 2010.

9. Актуальные проблемы противодействия коррупции: материалы международной научно-практической конференции, 14 октября 2010 г. / Отв. ред.: Амельчаков И.Ф.-Белгород: ООНИ и РИД БелЮИ МВД России, 2010.

10. Антикоррупционная политика России. Криминологические аспекты: В. В. Астанин - Санкт-Петербург, ЮнитиДана, Закон и право, 2009 г.

11. Билинская М.Н. Современная коррупция: отечественная специфика и зарубежный опыт противодействия / М.Н. Билинская, В.В. Моисеев, В.Ф. Ницевич; Орловская региональная академия гос. службы.-Орел, 2011.

12. Борьба с коррупцией: новые подходы и векторы современного развития: материалы Всероссийской научнопрактической конференции, Россия, Волгоград, 15-25 ноября 2010 г. / Отв. ред.: Чуриков В.В.-Волгоград: Изд-во ВолГУ, 2011.

13. Взаимодействие институтов гражданского общества и органов местного самоуправления в сфере противодействия коррупции: материалы Всероссийского межвузовского круглого стола, г. Нижнекамск, 23 декабря 2011 г. / Отв. ред.: Агапов О.Д., Кабанов П.А.-Казань: Познание, 2012.

14. Вовлеченность институтов гражданского общества в антикоррупционную деятельность органов публичной власти Республики Татарстан: аналитический доклад / Рук. авт. коллектива П.А. Кабанов; под науч. ред. П.А. Кабанова и И.И. Бикеева. - Казань, 2011. - 27 с. (публикация доступна на личном блоге П.А.Кабанова http://crimpravo.ru/blog/1064.html).

15. Волженкин, Б. В. Коррупция. - СПб.: СПбЮИ, 1998.

16. Куракин А.В. Международное и административное право и противодействие коррупции в системе государственной гражданской службы // NB: Административное право и практика администрирования. - 2014.1. - C. 53 - 81. DOI: 10.7256/2306-9945.2014.1.11051. URL: http://www.e-notabene.ru/al/article_11051.html

\section{References (transliterated):}

1. Bukalerova L.A., Kopylov M.N. K voprosu o ponyatii «korruptsionnye prestupleniya» Obshchestvo i pravo. 2012. № 1. S. 105-109.

2. Bukalerova L.A., Gavryushkin Yu.B. K voprosu o vvedenii instituta ugolovno-pravovogo vozdeistviya v otnoshenii yuridicheskikh lits // Probely v rossiiskom zakonodatel'stve. 2012. № 4. S. 169.

3. Zakon Velikobritanii o korruptsii v gosudarstvennykh organakh $1889 \mathrm{~g}$.

4. Ragulina A.V., Spasennikov B.A. Chelovek (fizicheskoe litso) kak sub"ekt prestupleniya.// Chernye dyry v rossiiskom zakonodatel'stve. №2. 2003;

5. Ugolovnoe zakonodatel'stvo zarubezhnykh gosudarstv v bor'be s korruptsiei / Institut zakonodatel'stva i sravnitel'nogo pravovedeniya pri Pravitel'stve Rossiiskoi Federatsii. Pod red. Vlasova I.S. M. 2009. S.31.

6. Aktual'nye problemy obespecheniya zakonnosti i protivodeistviya korruptsii v sisteme Ministerstva vnutrennikh del Rossiiskoi Federatsii. T. 3 / Kostennikov M.V., Kurakin A.V., Ovchinnikov N.A.-M.: Maroseika, 2012.

7. Aktual'nye problemy bor'by s ekstremizmom, terrorizmom i korruptsiei: materialy mezhvuzovskoi nauchno-prakticheskoi konferentsii, 12 maya 2011 g., g. Astrakhan' / Otv. red.: Bichekhvost A.F., Petrashova O.I., Pushkin A.I.-Astrakhan': Sorokin Roman Vasil'evich, 2011.

8. Aktual'nye problemy bor'by s korruptsiei v stranakh SNG / Karpovich O.G., Nikolaev A.T., Spirin M.S.-M., 2010.

9. Aktual'nye problemy protivodeistviya korruptsii: materialy mezhdunarodnoi nauchno-prakticheskoi konferentsii, 14 oktyabrya 2010 g. / Otv. red.: Amel'chakov I.F.-Belgorod: OONI i RID BelYuI MVD Rossii, 2010.

10. Antikorruptsionnaya politika Rossii. Kriminologicheskie aspekty: V. V. Astanin - Sankt-Peterburg, Yuniti-Dana, Zakon i pravo, $2009 \mathrm{~g}$.

11. Bilinskaya M.N. Sovremennaya korruptsiya: otechestvennaya spetsifika i zarubezhnyi opyt protivodeistviya / M.N. Bilinskaya, V.V. Moiseev, V.F. Nitsevich; Orlovskaya regional'naya akademiya gos. sluzhby.-Orel, 2011.

12. Bor'ba s korruptsiei: novye podkhody i vektory sovremennogo razvitiya: materialy Vserossiiskoi nauchno-prakticheskoi konferentsii, Rossiya, Volgograd, 15-25 noyabrya 2010 g. / Otv. red.: Churikov V.V.-Volgograd: Izd-vo VolGU, 2011.

13. Vzaimodeistvie institutov grazhdanskogo obshchestva i organov mestnogo samoupravleniya v sfere protivodeistviya korruptsii: materialy Vserossiiskogo mezhvuzovskogo kruglogo stola, g. Nizhnekamsk, 23 dekabrya 2011 g. / Otv. red.: Agapov O.D., Kabanov P.A.-Kazan': Poznanie, 2012.

14. Vovlechennost' institutov grazhdanskogo obshchestva v antikorruptsionnuyu deyatel'nost' organov publichnoi vlasti Respubliki Tatarstan: analiticheskii doklad / Ruk. avt. kollektiva P.A. Kabanov; pod nauch. red. P.A. Kabanova i I.I. Bikeeva. Kazan', 2011. - 27 s. (publikatsiya dostupna na lichnom bloge P.A.Kabanova http://crimpravo.ru/blog/1064.html).

15. Volzhenkin, B. V. Korruptsiya. - SPb.: SPbYuI, 1998.

16. Kurakin A.V. Mezhdunapodnoe i administrativnoe pravo i protivodeistvie korruptsii v sisteme gocudapctvennoi grazhdanskoi sluzhby // NB: Administrativnoe pravo i praktika administrirovaniya. - 2014. - 1. - S. 53 - 81 . DOI: 10.7256/2306-9945.2014.1.11051. URL: http://www.e-notabene.ru/al/article_11051.html 